\title{
Bayat, Çorum, tarım alanlarının verimlilik parametrelerinin yersel değişkenliğinin belirlenmesi
}

\author{
Determination of spacial variability of soil fertility parameters in ag-lands of Bayat District, Çorum
}

\author{
Sinem SEZER HIZ ${ }^{1}$, Veli UYGUR ${ }^{2}$ (iD \\ ${ }^{1}$ Akdeniz District Directorate of Agriculture and Forestry, Mersin, Türkiye. \\ ${ }^{2}$ Department of Soil Science and Plant Nutrition, Faculty of Agriculture, Iğdır University, Iğdır, Türkiye
}

\section{MAKALE BILGISI / ARTICLE INFO}

\section{Makale tarihçesi / Article history:}

DOI: $10.37908 /$ mkutbd.753778

Geliş tarihi /Received:16.06.2020

Kabul tarihi/Accepted:17.08.2020

\section{Keywords:}

Soil fertility, Spatial dependence, Kriging, Bayat, Çorum, Soil properties.

\footnotetext{
Corresponding author: Veli UYGUR

$\bowtie$ : veliuygur@isparta.edu.tr
}

\section{Ö Z E T / A B S T R A C T}

\footnotetext{
Atıf / Citation: Sezer Hız S, Uygur V (2020) Bayat, Çorum, Tarım Alanlarının Verimlilik Parametrelerinin Yersel Değişkenliğinin Belirlenmesi. MKU. Tar. Bil. Derg. 25(3) : 443-454. DOI: 10.37908/mkutbd.753778
}

\section{GiRiş}

Topraklar, toprak yapan faktörlerin kombinasyonunun değişmesine bağıı olarak kısa mesafeler içerisinde farklı özellikler göstermektedir (Dobermann ve ark., 1995). Bunun yanında tarım topraklarında farklı amenajman sistemlerinin uygulaması da toprak özelliklerinde önemli varyasyonların ortaya çıkmasına neden olmaktadır (Duan ve ark., 2020; Alves ve ark., 2019; Wu ve ark., 2019; Sawant ve ark., 2018). Kısa mesafelerde çiftlik bazlı yapılan uygulamalarda toprak özellikleri ve verimliliğinde farklılı̆ın ortaya çıkmasında etken olmaktadır (Wasu ve ark., 2017). Topraklardaki bu değişkenlik, genellikle toprak oluşturan faktörlerin kombinasyonundaki değişikliğe ki bu da genelde bir referans noktadan artan uzaklığa bağlı bir fonksiyon olarak tanımlanabilmektedir (Miheretu ve Yimer, 2018). Ancak, herhangi bir özelliğin ya da toprağın tüm özelliklerinin arazide nasıl bir değişkenlik gösterdiğinin belirlenmesi her zaman toprak bilimciler için önemli bir problem olmuştur. Zira incelenecek olan toprak özelliğinin arazinin tüm noktalarında nasıl bir değişkenlik gösterdiğinin belirlenmesi sonsuz sayıda toprak örneklemesini gerektireceğinden böyle bir işlemin yapılması olası 
değildir. Bu nedenle kabul edilebilir bir hata payı ile uygun bir örnekleme sistemiyle alınmış temsili toprak örneklerinin seçilmesi ve ortaya çıkan değişimlerin modellemelerle belirlenmesi daha uygulanabilir bir durumdur (Webster ve Oliver, 2007).

Belirlenen bir toprak özelliğinin belirli bir noktadaki değeri, aslında o parametrenin söz konusu noktadaki uzaysal konumunun bir fonksiyonudur. Başka bir deyişle bu yaklaşım, toprak özelliklerinin arazide süreklilik gösterdiğini bildirmektedir. Herhangi bir toprak özelliğinin mesafeye bağlı değişimi incelendiğinde birbirine yakın olan örneklerin parametre değerlerinin uzak olan örneklerinkine göre daha fazla benzerlik gösterdiği belirlenmiştir (Hamlett ve ark. 1986). Bu nedenle havza bazında veya ova bazında yapılacak olan araştırmalarda alınacak olan toprak örneklerinin arasındaki mesafenin dikkate alınması gerekmektedir. Bu şekilde minimum sayıda örnekleme ile maksimum miktarda anlamlı toprak verisi üretebilmek ve geniş alanlarda uzun dönemli planlama, problem veya risklerin belirlenmesi, arazideki değişkenliğe göre gübreleme uygulamalarının oluşturulabilmesi gibi birçok veri jeostatistik yöntemler kullanılarak elde edilebilmektedir (Duan ve ark., 2020; Behera ve ark., 2018; Cheng ve ark., 2018; Sawant ve ark., 2018).

Yaygın uygulamada çiftçiler arazilerinin homojen olduğunu düşünerek toprak ve bitki amenajmanı uygularlar ve bunun sonucunda da arazideki değişkenliklerden dolayı bazı bölgelerde yetersiz bazı bölgelerde de aşırı uygulamaların ortaya çıkmasına neden olur. Bu da pratikte belirli alanlarda çevresel riski arttırırken, belirli alanlarda da verimi düşürmektedir. Bu nedenlerle girdi kullanımı artmakta, yapılan tarımın ekonomik değeri ve sürdürülebilirliği azalmakta, çevre kirliliği ve gereksiz enerji kullanımı artmaktadır (Sawant ve ark., 2018; Huang ve ark., 2017; Cheng ve ark., 2014; Castrignano ve ark., 2000). Toprak verimliliğiyle ilgili parametreler çok dar alanlarda, hatta birkaç metre mesafe de bile, önemli değişimler gösterebilir (Qiu ve ark., 2016). Nem, yarayışlı fosfor, A-horizonunun derinliği, değişebilir Na yüzdesi, elektriksel iletkenlik gibi parametrelerdeki değişkenlik düz düze yakın bir tarla da bile önemli varyasyonlar gösterebilir (Rockstrom ve ark., 1999; Goderya, 1998). Hatta sözü edilen parametreler karık veya damla sulamanın uygulandığı bir tarımsal faaliyette metreler içerisinde bile önemli değişimler gösterebilir. Bu durumda özellikle toprakta hareketliliği yüksek olan nitrat, sodyum ve nem içeriği gibi parametreler çok kısa mesafelerde son derece değişkendir (Shahandeh ve ark., 2005; Stenger ve ark., 2002; Manning ve ark., 2001; Goderya, 1998). Hatta tuzluluk aynı noktada su rejiminde meydana gelen değişimlere bağlı olarak sulama-buharlaşma döngüsünde bitki gelişimini etkileyebilecek kadar değişim gösterebilmektedir (Yalçın, 2012; Usta, 1995). Organik madde içeriği, kil içeriği ve verimlilik gibi parametrelerin çiftlik bazındaki değişkenliğinin bilinmesinin iyi bir başlangıç noktası olduğu bildirilmektedir (Heijting ve ark., 2011). Diğer taraftan politika üreticileri için geniş ölçeklerde durumun ortaya konulması da problemli alanların belirlenmesi ve girdi yönetimi açısından önemli bir ihtiyaçtır.

Kompozit toprak örneklerinde incelenen bazı toprak parametreleri dar alanlarda oldukça değişken iken, örnekleme mesafesinin artmasıyla bu değişkenlikte önemli derecede azalmalar ortaya çıkmaktadır (de Oliveira ve ark., 2010). Diğer taraftan eğimli arazilerde ise jeomorfolojik birimler ile haritalama birimleri dikkate alınarak yapılan kompozit örneklerin bile araziyi tanımlaması son derece yetersiz olabilmektedir (Miheretu ve Yimer, 2018). Bu durum geniş ölçekli arazilerde örnekleme yoğunluğunun amaçlar doğrultusunda belirlenebilmesi için kritiktir.

Farklı arazi kullanım koşullarında toprakların toplam azot ve fosfor içeriğini incelemişlerdir (Wang ve ark., 2009). Liudaogou havzasından $\left(6.89 \mathrm{~km}^{2}\right)$ aldıkları 689 yüzey toprağında klasik istatistik ve jeoistatistik kullanarak platodaki tarım, çayır ve çalılık alanların topraklarının mesafeye bağlı toplam azot ve fosfor içeriklerinin heterojenliklerini ortaya koymuşlardır. Çayır örtüsü altındaki topraklar hariç diğer kullanımlarda azot ve fosfor içeriği normal dağılım göstermiştir. Toprakların azot içeriklerinin organik madde içeriğiyle, toplam fosfor içeriği ise daha çok ince taneciklerin miktarı ile ilişkili bulunmuştur. Farklı arazi kullanım koşullarında her iki parametre de orta derecede bir değişkenlik göstermiştir ve sıralama azdan çoğa doğru; tarım alanı, çayır ve çalılık olarak belirlenmiştir.

Yukarıdaki literatürler göz önünde bulundurularak Çorum ili Bayat ilçesi tarım alanlarının mevcut verimlilik durumu ve verimliliği kısıllayan problemlerin belirlenmesi ve daha ekonomik ve çevre dostu tarımsal uygulamaların yapıımasına ışık tutmak üzere bu çalışma planlanmıştır. Bu çalışmanın gerek yöredeki ziraat mühendislerinin stratejik çalışmalarında gerekse yörenin detaylı bir verimlilik envanteri olarak kullanılabileceği düşünülmektedir.

\section{MATERYAL ve YÖNTEM}

\section{Çalışma Alanının Özellikleri}

Çorum Ili Türkiye tarım Havzaları içerisinde Yeşilırmak Havzası ve Orta Kızılırmak Havzası'nda bulunmaktadır. Çorum ili Merkez İlçesi, Bayat, Dodurga, İskilip, Kargı, 
Laçin, Mecitözü, Oğuzlar, Ortaköy ve Osmancık ilçeleri Yeşilırmak Havzası içerisinde yer almaktadır (Anonim 2009, Anonim 2010). Bayat iliçesi 41 derece kuzey paralellerinin güneyinde, 34 derece Doğu Meridyeninin doğusunda Karadeniz bölgesi ile icç Anadolu bölgesinin kesim noktasında Köroğlu Dağlarının doğuya uzantısı ile İ̧ Anadolu'nun Orta Kızılırmak bölümünde yer almaktadır. Bayat ilçesine Doğuda İskilip ve Uğurludağ, güneyinde Sungurlu, Batıda Çankırı Merkez ilıçe ve Yapraklı, Kuzeyde de Kastamonu'nun Tosya İlçesi komşudur. Yüzölçümü $784 \mathrm{~km}^{2}$ dir. İlçe merkezinde rakım 625 m'dir. İlçenin kuzeyinde yer alan Karatepe' de rakım $1400 \mathrm{~m}$ ve Öbektepe'de rakım 2013 m’yi bulmaktadır. İlçe merkezinin güney-batısında yer alan Asmatepesi'nde rakım $1270 \mathrm{~m}$ olup güneye doğru gidildikçe rakım 500 m'ye kadar düşmektedir. Bu nedenle Bayat İlçesinin Kuzeyi dağlık, Güney kümeler halinde tepelerin ve kısmen ovaların yer aldığı kırık, dalgalı ve engebeli bir arazi yapısı yer almaktadır.

\section{Toprak Örneklerinin Alınması ve Hazırlanması}

Çorum'un Bayat ilç̧esinde belirlenen örnekleme alanından $700 \times 700 \mathrm{~m}$ aralıklarla ızgara sistemi ile gritler oluşturulmuştur. Oluşturulan gritlerin kesişim noktalarının koordinatlarından (Şekil 1) GPS aleti ile tarım arazisi olarak kullanılan yerlerden buğday hasadı sonrasında yüzey toprağı $(0-20 \mathrm{~cm})$ örneklenmiştir. Hava kuru hale getirilen toprak örnekleri tanımlayıcı analizleri için $2 \mathrm{~mm}$ 'lik elekten elenmiştir.

\section{Toprak Örneklerinde Yapılan Analizler}

Toprak örneklerinde tanımlayıcı toprak özelliklerinden organik madde, yarayışlı fosfor, toplam azot, elektriksel iletkenlik, değişebilir katyonlar, tekstür, pH, kireç parametreleri Kacar (2012)'da bildirilen yöntemlerle belirlenmiştir. Toprak tekstürü Bouyoucos hidrometre yöntemi ile, toprak reaksiyonu $(\mathrm{pH})$ ve iletkenliği $(\mathrm{EC})$ 1:2.5' lik toprak su süspansiyonunda, katyon değişim kapasitesi (KDK) amonyum asetatla $(1 \mathrm{~N}, \mathrm{pH}=7.0)$ ekstrakstrakte edilen değişebilir katyonların miktarından çözünebilir katyonların miktarı çıkartılarak elde edilen katyonların miktarlarının toplamından hesaplanmıştır (Rhoades, 1982), kireç eşdeğeri $\left(\mathrm{CaCO}_{3}\right)$ Scheibler kalsimetresi ile, organik madde modifiye edilmiş WakleyBlack yöntemiyle, yarayışlı fosfor $0.5 \mathrm{M} \mathrm{pH}^{\prime}$ sı 8.5 ayarlı $\mathrm{NaHCO}_{3}$ çözeltisiyle (1: 20 oranında toprak: çözelti) ekstrakte edilmiş ve askorbik asit yöntemiyle renklendirilerek, ekstrakte edilebilir katyonlar ( $\mathrm{Ca}, \mathrm{Mg}$, $\mathrm{Na}$ ve K) amonyum asetat yöntemi ile ekstrakte edilerek MP-AES cihazıyla belirlenmiştir.

\section{Verilerin Değerlendirilmesi ve Kriging Süreci}

Verilerde tanımlayıcı analizler yapılarak (Gama Design Software, 2008) normal dağılım göstermeyen veri setleri transforme edilerek normal dağılıma getirilmiştir. Toprak özelliklerine ait yersel değişkenliğin belirlenebilmesi için yarıvariogram analizi gerçekleştirilmiştir (Journel ve Huijbregts, 1978). Yarıvariogram, mesafeye karşı yarı değişkenliğin grafikle gösterimidir (Lark, 2003). Daha sonra bu deneysel variogram her bir değişken için teorik bir variograma uyarlanmış ve en yüksek $R^{2}$ (açıklanabilen varyans) ve en küçük RSS (residual sum of squares, kalıntı hatalar toplamının karesi) değerinin elde edildiği deneysel variogram en uygun model olarak belirlenmiştir (Wang, 1999). Model belirlendikten sonra örneklenmemiş noktalardaki değerler point kriging yöntemi (nokta tahmincisi) ile tahmin edilmiş ve krosvalidasyon (birebir doğrulama) süreciyle modeller doğrulanmıştır. Analiz edilen her bir toprak özelliği için mesafeye bağlı değişim haritaları oluşturulmuştur. Haritaların kabul edilebilirliği verilerin standart sapma değeri ile standart sapma haritasındaki en büyük standart sapma değerlerinin kıyaslanması ile değerlendirilmiştir. Tüm jeoistatistiksel analizler GS+ (Versiyon 9) Jeoistatistik paket programı ile yapılmıştır (Gamma Design Software, 2008).

Kriging interpolasyonu, minimum varyansla tarafsız tahmin yapmak için kullanılabilecek en iyi tahmincidir (Stein ve Corsten, 1991). Bu çalışmada en az 8 komşu nokta kullanılarak aşağıda verilen denklemle enterpolasyon yapılmıştır.

$$
Z_{O K}{ }^{*}\left(x_{0}\right)=\sum_{i=1}^{n} \lambda_{i} Z_{(x i)}
$$

$Z^{*}\left(x_{0}\right)$ değeri örneklenmemiş noktanın tahmin edilen değer, $N$ tahmini yapılan koordinattaki örnek değerinin tahmininde kullanılan komşu örnek nokta sayısı, $\lambda_{i}$ komşu örneğe $z\left(x_{0}\right)$ uygulanan ağırlık katsayısıdır. Ağırlık katsayıları $z^{*}\left(x_{0}\right)$ tahmini değerlerinin tarafsız olabilmesi için seçilirler. 

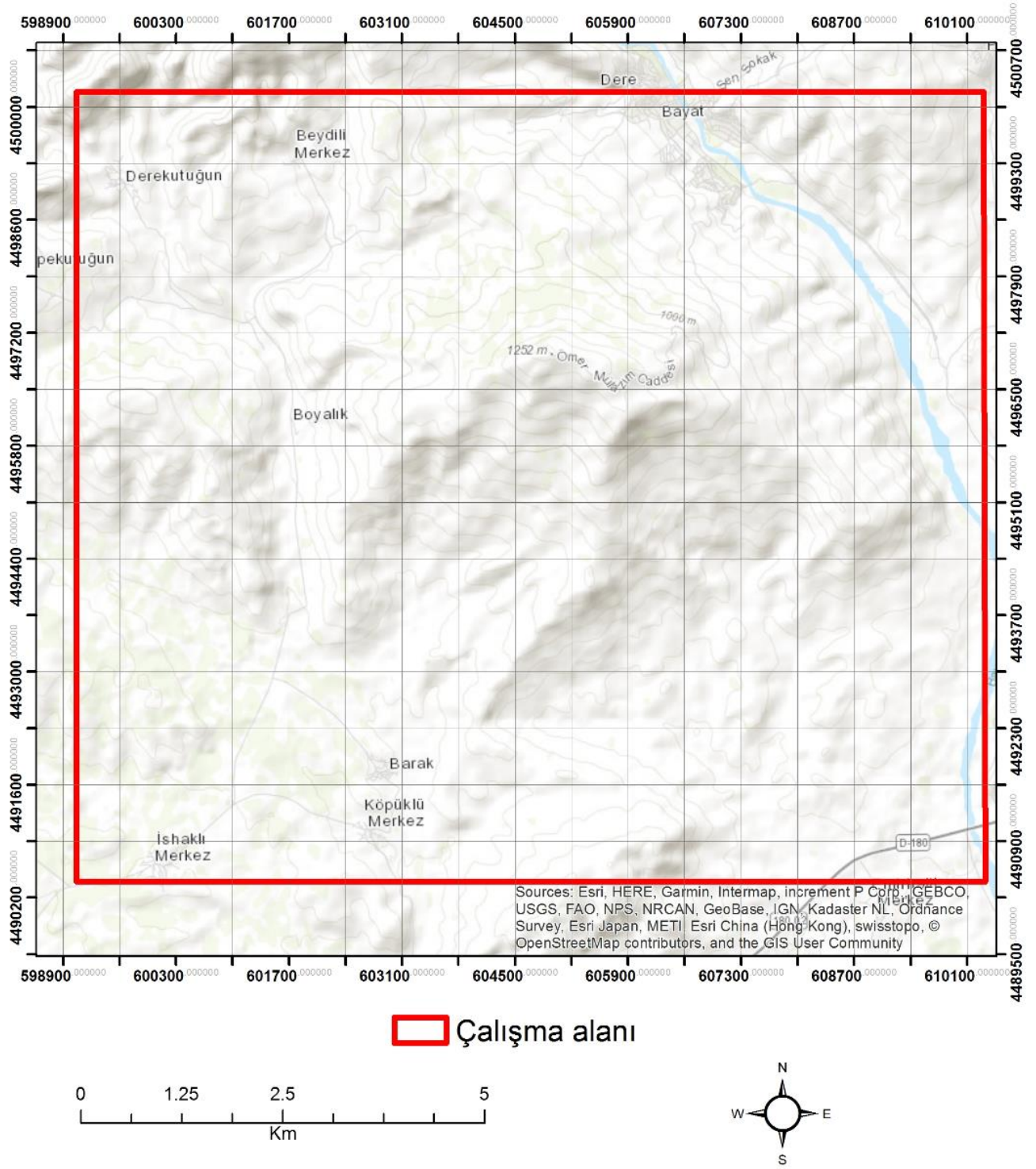

Şekil 1. Çalışma alanının topoğrafyası ve toprak örnekleme noktaları

Figure 1. Topography of the study area and soil sampling nodes

\section{BULGULAR ve TARTIŞMA}

\section{Tanımlayıcı İstatistikler}

Bayat ovasından alınan toprakların tanımlayıcı istatistik verileri Çizelge 1 'de verilmiştir. Topraklardaki bitkiye yarayışı potasyum içeriklerinin $\left(2100 \mathrm{mg} \mathrm{kg}^{-1}\right)$ yeterlilik seviyesinin $\left(370 \mathrm{mg} \mathrm{kg}^{-1}\right.$ ) çok üzerinde olduğunu göstermektedir. Zira FAO sınıflamasına göre $1 \mathrm{M}$ amonyum asetatla değişebilen $\mathrm{K}$ miktarı $370 \mathrm{mg} \mathrm{kg}^{-1}$ ın üzerinde olduğunda $\mathrm{K}$ miktarı yeterli, $1000 \mathrm{mg} \mathrm{kg}^{-1 \text { ' }}$ In üzerinde olduğunda ise çok yüksektir.

Topraklardaki yarayışlı P miktarı $2.013 \pm 0.40 \mathrm{mg} \mathrm{kg}^{-1}$ ile son derece düşüktür. Bitkiden bitkiye değişmekle beraber, Olsen yöntemiyle belirlenen fosfor miktarının yeterlilik sınırları 8-25 mg $\mathrm{P} \mathrm{kg}^{-1}$ olarak bildirilmiştir (Alpaslan ve ark., 2005). Bu da ova genelinde verimli bir bitki yetiştiriciliği için fosforlu gübreleme uygulanmasını gerekli kılmaktadır.

Varyasyon katsayısı sodyum $(\mathrm{Na})$ için diğer değişkenlere göre en yüksek bulunmuştur. Bu durum $\mathrm{Na}$ nın arazide mesafeye bağlı değişiminin yüksek olduğunu göstermektedir. Sodyum iyon konsantrasyonu arazinin topografyası, mineral çözünürlük, toprak nem potansiyeli, buharlaşma miktarı ve ana materyale bağlı olarak değişebilir. Toprak $\mathrm{pH}$ sı en düşük $\mathrm{CV} \%$ değerine (5.6) sahip olup, bu durum toprakların genelde kireçli olması ile ilişkili olduğu değerlendirilmiştir. Toprak pH'sı örnekleme sahasında nötr ve nötre yakın değerler alarak dağılmaktadır. Toprak pH'sından sonra ikinci en az değişkenlik gösteren toprak özelliği topraktaki toplam azot miktarıdır. Bunun varyasyon katsayısı da toprağın fosfor içeriğine ait CV değerine yakındır. Toprak organik maddesinin az olması ve toprağın azot kaynaklarınca fakir olması, kurak-yarı-kurak iklim ve organik madde 
girdisinin az olması ve çalışma sahasının boyutu bunda etken olmuştur. Bunun tersine toprak fosforu çiftlik bazlı uygulamaların farklılığı ve toprak oluşum süreçlerinin etkisi ile toplam azota göre daha yüksek CV göstermektedir. Toprak özellikleri içerisinde bir tek $P$ içeriği normal dağıııma çok yakındır (çarpıklık:-0.03). Dağılım fonksiyonunun simetrisine bakıldığında bütün toprak özellikleri asimetrik bir normal dağılım göstermişlerdir ve veri setinin çoğunluğu sola kuyruklu negatif çarpıklık değerlerine sahiptirler. Bunun anlamı birkaç tane küçük gözlem değeri büyük gözlem değerlerine göre daha sola yaslanmış olarak simetrik dağılımı bozmaktır. Benzer şekilde kurtosis değerleri de 2'den daha küçük olup normal dağılıma çok yakın bir dağılımı ifade etmektedirler. Burada toprak kireç içeriği dalgalanma göstermekte yani arazide bir tek dağııım göstermemektedir.

Çizelge 1. Bayat ovası topraklarının tanımlayıcı özellikleri Table 1. Descriptive statistics of Bayat Plain's soils

\begin{tabular}{cccccccc}
\hline Değişken & Ortalama & Std. Sapma & Min & Maksimum & Skewness & Kurtosis & CV (\%) \\
\hline $\mathrm{K}\left(\mathrm{mg} \mathrm{kg}^{-1}\right)^{\mathrm{a}}$ & 2100 & 520 & 770 & 3220 & -0.32 & -0.50 & 24.8 \\
$\mathrm{Na}\left(\mathrm{mg} \mathrm{kg}^{-1}\right)^{\mathrm{b}}$ & 3.680 & 1.611 & -1.61 & 9.05 & -0.37 & 0.48 & 43.8 \\
$\mathrm{P}(\mathrm{mg} \mathrm{kg})^{\mathrm{b}}$ & 2.013 & 0.4 & 0.99 & 2.96 & -0.03 & -0.30 & 19.9 \\
$\mathrm{Kireç} \mathrm{( \% )}$ & 3.537 & 0.852 & 0.32 & 5.2 & -0.96 & 1.72 & 24.1 \\
$\mathrm{pH}$ & 7.181 & 0.401 & 6.02 & 7.88 & -0.22 & -0.55 & 5.6 \\
$\mathrm{EC}(\mu \mathrm{S} / \mathrm{cm})$ & 464.2 & 585.8 & 113.0 & 3200 & 2.24 & 4.36 & 126.2 \\
$\mathrm{Kil}(\%)$ & 45.4 & 13.7 & 11.8 & 74.4 & -0.15 & -0.24 & 30.3 \\
$\mathrm{Silt}(\%)$ & 34.0 & 8.0 & 15.2 & 72.7 & 1.36 & 2.52 & 61.2 \\
$\mathrm{Kum}(\%)$ & 20.6 & 12.6 & 1.3 & 69.9 & 1.40 & 5.56 & 23.6 \\
\hline
\end{tabular}

${ }^{a}$ Karekök ve ${ }^{b}$ Ln dönüşümü yapılan değişkenler.

Toprakların mesafeye ve yer şekillerine bağlı en çok değişim gösteren EC parametresi 1:2.5 toprak su karışımında ortalama 464.4 ve 113 ile $3200 \mu \mathrm{S} / \mathrm{cm}$ arasında değişim göstermiştir. Ortalama değer irdelendiğinde ova genelinde tuzluluğun problem olmadığı ancak yaklaşık 15-20 örnekleme noktasında tuzluluğun bitki yetiştiriciliği açısından problem teşkil edebilecek seviyelerde olduğu düşünülmektedir (Alpaslan ve ark., 2005). Bu örnekleme noktaları genellikle çalışma alanının drenaj şartlarının iyi olmadığı yamaçlardan yıkanan materyallerin biriktiği çukur noktalarda olduğu gözlenmiştir. Arazide su hareketiyle çok yer değiştirmesine bağlı olarak ölçülen parametreler arasında en yüksek standart sapma ve varyasyon katsayısına sahip olmuştur. Benzer şekilde EC değerleri 2.52 skewness değeriyle birlikte pozitif yönde normal dağılımdan sapma göstermiştir.

Çalışma alanındaki toprakların tekstüründe kil fraksiyonu baskındır. Kil içeriği ortalama \%54.4 olup \%11.8 ile 74.4 arasında değişim göstermiştir. Silt fraksiyonu topraklarda ortalama \%34 oranında bulunurken, maksimum $\% 72.7$ ve minimum $\% 15.2$ olarak bulunmuştur. Kum fraksiyonun ortalama bulunuşu \%20.6 iken minimum değer \%1.3, maksimum değer \%69.9 olarak tespit edilmiştir. Toprakların tekstür bileşenlerinden kil, silt ve kum oranları genel itibarıyla 2'nin altındaki çarpıklık değerleriyle normal dağılım göstermiştir. Varyasyon katsayıları kum da daha az olmakla birlikte bunu kil ve silt takip etmiştir (Çizelge 1). $E C$, silt ve kum içerikleri ise diğer verilerden farklı olarak pozitif çarpıklık değeri göstermişlerdir. Bu da bu parametrelerin çalışma sahasının belirli kısımlarında genele göre yüksek değerlere sahip olduğunu göstermektedir.

\section{Toprak Özelliklerinin Mesafeye Bağlı Değişimini Tanımlayan Modeller ve Parametreleri}

Bayat Ovası topraklarının özelliklerinin mesafeye bağlı değişkenliğini tanımlayan modeller ve model parametreleri Çizelge 2'de verilmiştir. Toprak kireç içeriği (Küresel model) hariç bütün toprak özellikleri üstel modele göre mesafeye bağlı değişim göstermektedirler. Toprak potasyum içeriği, kireç ve pH'sı 650 m mesafede bir komşuluk ilişkisi örneklemesi yapılarak dağılım desenleri oluştururken, toprak azotu $(660 \mathrm{~m})$, toprak fosfor içeriği $(900 \mathrm{~m})$ ve toprak sodyum içeriği $(1200 \mathrm{~m})$ çap içerisinde bulunan örneklerle dağılım deseni oluşturmuşlardır. Bu durumda sodyum iyonunun dağııım ortalaması daha fazla örnek sayısıyla yapılmıştır. Üstel modellerin range değerleri gerçek model range değerleri olmayıp range parametresi değerleridir. Üstel modeller için gerçek range değerleri variogram grafiğinde mesafeye bağlı değişimin \%95 inin geçildiği noktadaki mesafe değeri olarak kabul edilmektedir. 
Çizelge 2. Toprak özelliklerinin mesafeye bağlı değişim modelleri ve model parametreleri

Table 2. Spatial variation models of soil properties and their parameters

\begin{tabular}{cccccccccc}
\hline Değişkenler & Model & $\begin{array}{l}\text { Örnekleme } \\
\text { Çapı }(\mathbf{m})\end{array}$ & Nugget & Sill & Range & $\mathbf{C} / \mathbf{C O}+\mathbf{C}$ & $\mathbf{R}^{2}$ & RSS & $\begin{array}{c}\text { Bağımlılık } \\
\text { Derecesi }\end{array}$ \\
\hline $\mathrm{K}\left(\mathrm{mg} \mathrm{kg}^{-1}\right)$ & Üstel & 650 & $2.155 \mathrm{E}-003$ & $4.32 \mathrm{E}-003$ & 23000 & 0.501 & 0.453 & $5.82 \mathrm{E}-7$ & Orta \\
$\mathrm{Na}\left(\mathrm{mg} \mathrm{kg}^{-1}\right)$ & Üstel & 1200 & 0.8800 & 3.0640 & 2650 & 0.738 & 0.961 & 0.14 & Orta \\
$\mathrm{P}\left(\mathrm{mg} \mathrm{kg}^{-1}\right)$ & Üstel & 900 & 0.1395 & 0.2800 & 31100 & 0.502 & 0.170 & $1.39 \mathrm{E}-3$ & Orta \\
$\mathrm{N} \mathrm{( \% )}$ & Üstel & 660 & 0.0042 & 0.0089 & 31100 & 0.525 & 0.528 & $2.11 \mathrm{E}-6$ & Orta \\
Kireç (\%) & Küresel & 650 & 0.3950 & 1.6830 & 31100 & 0.777 & 0.831 & 0.088 & Kuvvetli \\
pH & Üstel & 650 & 0.0864 & 0.1838 & 3140 & 0.530 & 0.813 & $1.65 \mathrm{E}-3$ & Orta \\
Kil (\%) & Üstel & 1073 & 28.7 & 200.1 & 1440 & 0.857 & 0.696 & 4282 & Kuvvetli \\
Kum (\%) & Üstel & 1073 & 0.1532 & 0.4324 & 1970 & 0.646 & 0.751 & 0.0115 & Orta \\
\hline
\end{tabular}

Mesafeye bağlı değişim modellerinden üstel modellerin hepsi örnek çiftleri arasında orta kuvvette bir korelasyon $(\mathrm{C} / \mathrm{C} 0+\mathrm{C})$ göstermektedirler. Toprak kireç içeriği küresel modele göre dağılım göstermekte olup modelin range parametresi $31100 \mathrm{~m}$ değerine eşittir. Fosfor, azot ve kireç içerikleri örnek çiftleri arasındaki maksimum korelasyon mesafesi (range) değerlerine sahip olmakla beraber bu mesafe bu üç değişken kireç ile aynıdır. Bunları potasyum, $\mathrm{pH}$ ve sodyum izlemektedir. Başka bir deyişle, toprak fosfor, azot ve kireçörnek çiftleri arasında 31100 m mesafeye kadar ilişki kurulabilir ve örnekler bir birlerine bu mesafeden sonra herhangi bir korelasyon oluşturmaz ve benzemezler. Benzer şekilde toprak bu üç değişken için orta ve kuvvetli derecede homojendir. Bu sonuç, alınan bir kireç, fosfor ve azot örneği 31100 m uzunluğunda bir düzlemi temsil etme yeteneğinde olduğu anlamına da gelmektedir.

Bayat Ovasında sodyumun diğer değişkenlere göre daha kısa mesafelerde değiştiği ve toprağın sodyum açısından bir soruna sahip olduğu görülmektedir. Çünkü sodyumun sill değeri (mesafeye bağlı örnek varyansı) en az 1 ile 709 defa diğer değişkenlerin sill değerlerinden büyüktür. Bu durum toprağın sodyum açısından iyi yönetilmesini gerektirmektedir. Bu çalışma sahasında bir tek kireç çok kuvvetli bir mesafeye bağlı dağılım ilişkisi göstermektedir. Bu durum kirecin arazide dominant bir faktör olduğunu ve anamateryal ve sekonder karbonatlardan kaynaklanabileceğini göstermektedir. Bölgenin kurak-yarı kurak iklime sahip olması nedeniyle karbonatların toprak profilinden yıkanamaması ve toprak oluşumunda kalsifikasyon sürecinin etkin olduğu da gözlenmektedir. Model nugget değerleri (mesafeye bağlı olmayan varyans değerleri) enstrümantal analiz yöntemleri, ölçme hataları, ölçüm cihazlarındaki hatalar ve insan kaynaklı hatalardan ortaya çıkmakta olduğundan bu hataların toplamı nugget varyans olarak tanımlanır. Genellikle arazideki örnekleme mesafesinden daha az mesafeye sahip olan örneklerden kaynaklanmaktadırlar (650 m den daha az mesafedeki örnek noktaları). Modellerin nugget değerleri en azdan en yükseğe doğru $\mathrm{K}, \mathrm{N}, \mathrm{pH}, \mathrm{P}, \mathrm{Na}$ ve $\mathrm{CaCO}_{3}$ sıralamasıyla değişmektedirler. Bu nedenle nugget değerleri rastgele değişim göstermektedirler. Modellerin mesafeye bağlı değişim varyansları incelendiğinde, modellerin sill değerleri $\mathrm{K}, \mathrm{N}, \mathrm{pH}, \mathrm{P}, \mathrm{CaCO}_{3}$ ve $\mathrm{Na}$ sıralamasını göstermektedir. Bu da sodyum açısından bu çalışma sahasının yönetim planlamasına ihtiyacı olduğuna işaret etmektedir.

Deneysel variogramların teorik variogramlara uyarlanması (fitting process) sürecinin göstergeleri olarak $\mathrm{R}^{2}$ ve RSS değerleri kullanılmıştır. Ancak bu değerler birbirleriyle karşılaştırılmasının yapılması uygun değildir (Webster ve Oliver, 2007). Çünkü bu değerler modellerin geliştirilmesi sürecindeki modelin uygunluğunun seçiminde rol oynamaktadırlar. Burada $\mathrm{R}^{2}$ nin mümkün olduğunca yüksek ve RSS' nin de mümkün olan en düşük seviyede ama bir ve daha düşük olması gözetilmelidir. Buna göre RSS değeri en yüksek olan model tahmin yaparken daha fazla hata yapma yeteneğindedir. Örneğin, mesafeye bağlı değişkenliğin yüksek ve heterojenliğin fazla olması nedeniyle sodyumun dağıımı daha fazla bir hatayla tahmin edilmektedir.

Kumun arazideki dağılımını gösteren model üstel model olarak bulunmuştur. Kum ve kil örnekleme çapı 1073 m alınarak bu mesafe içine düşen komşu örnek çiftleri ile tahminler yapılmıştır. Kum içeriğinin model parametrelerinden sillin nuggete oranı 2.8 olarak bulunmuştur. Başka bir deyişle örneğin varyansı, mesafeye bağlı olmayan örnek varyansının (nugget) 2.8 katıdır. Kil içeriği ile kıyaslandığında toprağın kum içeriği, kil içeriğine oranla orta güçte bir mesafeye bağlı değişim modeli ile haritalanmıştır. Örnekler arasındaki mesafeye bağlı değişkenlik, kilde daha yüksekken kumda daha azdır. Buna rağmen kum örnekleri arasındaki korelasyon mesafesi (range), kile göre daha yüksektir (1970 m). Kil içeriği fraksiyon olmayıp 100 ile çarpılmıştır. Bu nedenle kil içeriğine ait model parametreleri çok yüksek 
görünmektedir. Kilin dağılımını inceleyen mesafeye bağlı değişim modeli üstel model olup örnekler arasındaki mesafeye bağı değişkenliğin kuvvetli olduğunu göstermektedir. Başka bir deyişle örnekler arasındaki değişkenliğe ait varyansın çok büyük bir kısmı (\%86) mesafeye bağlı değişim modeli tarafından açıklanabilmektedir. Modelin sill değeri nugget değerinin en az 7 katıdır. Bu da gösteriyor ki açıklanamayan varyans, toplam varyansın yalnızca küçük bir kısmıdır. Kil örnekleri arazide en fazla $1440 \mathrm{~m}$ etkileşim mesafesi (kolerasyon mesafesi) içinde bulunmaktadır.

\section{Toprak Özelliklerine Ait Jeoistatistik Haritalar}

Potasyum: Toprakların K konsantrasyonlarının çalışma alanı içerisindeki örneklenen noktalardan tahmin edilmesi için en uygun semivariogram model parametreleri dikkate alınarak elde edilmiş ve $\mathrm{K}$ tahmin değerlerinin 270-750 mg kg-1 arasında değiştiği belirlenmiştir. Topraktaki K'nın çözünürlüğü, hareketliliği, bitkiler tarafından alınabilirliği üzerine etki eden çeşitli faktörler mevcuttur. Bu faktörler; toprağın yapısı, toprak pH'sı, arazinin sulanabilirliği, iklim vs. gibi etmenlerdir (Kacar, 2013). Aşamalı regresyon, verim değişkenliği ve topoğrafya çalışma yapılan alanlarda etkiye sahip olup; topoğrafya, kil içeriği, $\mathrm{P}$ ve $\mathrm{K}$ toprak test seviyelerini temsil eden temel bileşenler ile açıklanabilmiştir (Uygur ve ark., 2010). Bayat ilıçesinde yapılan çalışmalarda elde edilen ölçümler sonucunda $\mathrm{K}$ değerini gösteren bir harita elde edilmiş olup $\mathrm{K}$ değerleri saptanarak yoğunluklarına göre renklendirilip Şekil 2'deki haritada gösterilmiştir.

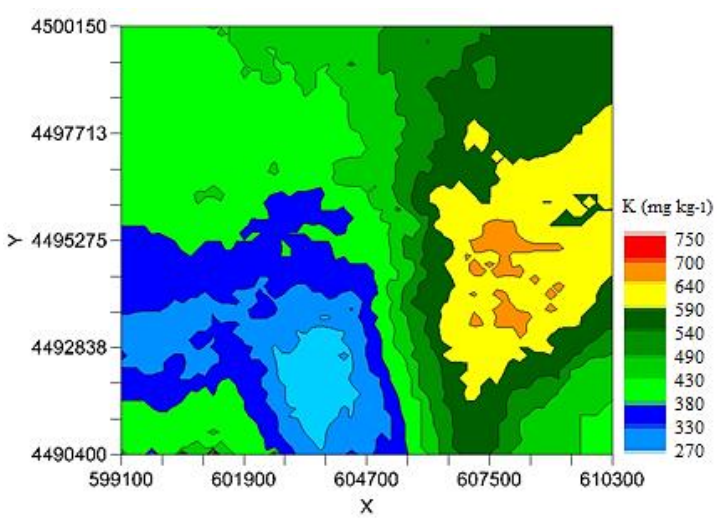

Şekil 2. Toprakların yarayışlı K konsantrasyonunun değişim paterni

Figure 2. Spatial pattern of available $K$ concentration in soils

Harita incelendiğinde mavi ve tonlarının olduğu bölge $\mathrm{K}$ değeri bakımından $270-380 \mathrm{mg} \mathrm{kg}^{-1}$ arasında çıkmıştır. $\mathrm{Bu}$ değerler $\mathrm{K}$ için toprakta istenilen değerlerdir ve bölgenin güney-batı kısmında toplanmıştır (Şekil 2). Ana materyaldeki ve topoğrafyadaki değişimlerden kaynaklandığı değerlendirilen, tarımın daha az yapıldığı ve yerleşim alanlarına yakın olan kısımlarda $K$ konsantrasyonları artış göstererek 380-750 mg kg-1 arasında çıkmıştır. Bu da haritada geniş bir alanı kapsayarak daha çok çalışma alanının batı bölgesinde toplanmıştır.

Sodyum: Toprakların $\mathrm{Na}$ değerlerinin çalışma alanı içerisindeki örneklenen noktalardan tahmin edilmesi için en uygun semivariogram model parametreleri dikkate alınarak elde edilmiş (Sezer, 2013) ve $\mathrm{Na}$ tahmin değerlerinin 39.6 - $371 \mathrm{mg} \mathrm{kg}{ }^{-1}$ arasında değiştiği belirlenmiştir (Şekil 3).

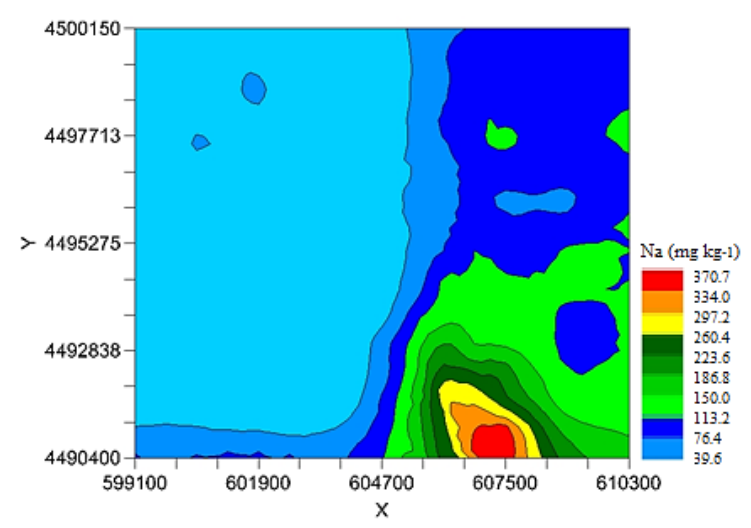

Şekil 3. Toprakların ekstrakte edilebilir $\mathrm{Na}$ konsantrasyonunun değişim paterni

Figure 3. Spatial pattern of extractable $\mathrm{Na}$ concentration in soils

Toprakta sodyumun en önemli kaynağı ana materyal olup, topografya belirli alanlarda artan konsantrasyonlara ya da yıkanmalara neden olabilmektedir. Sodyumun olumsuz etkisi: kil fraksiyonunun sahip olduğu denge bozucu etki ile $\mathrm{Mg}$ ve $\mathrm{Na}$ yüzeyi kaplar ve toprak altındaki su seviyeleri doygunluk, su infiltrasyonu ve fide çıkışını etkiler (Voortman ve ark., 2004). Çalışma alanında yüksekliğin fazla olduğu yerlerde yağış ve akarsular nedeniyle $\mathrm{Na}$ iyonunu yıkayarak daha düz eğimli arazilerde birikme gösterir (Şekil 3). Bu birikme nedeniyle $\mathrm{Na}$ iyonu konsantrasyonu düz alanlarda potansiyel problem olma eğilimindedir. Buharlaşmanın yüksek olması da bu riski daha fazla arttırmaktadır. Bu da çalışma sahasının güney doğu kesiminde yoğunlaşmıştır. İlginçtir ki bu alanlarda pH göreceli olarak daha düşüktür. Çalışma sahasının bu kısımlarında tuzluluğunda yüksek olması nedeniyle ya da $\mathrm{Cl}$ ve $\mathrm{SO}_{4}$ anyonlarının eşlik ettiği $\mathrm{Na}^{\prime}$ nın etkisi ile $\mathrm{pH}^{\prime}$ nın nötr civarında olmasına neden olmaktadır (Usta, 1995). Buna karşılık pH' nın 7.7 civarında olduğu yüksek kesimlerde (Şekil 1) yıkanma başat olduğundan $\mathrm{Na}$ 
uzaklaşmakta ve karbonatların/kirecin etkisi ile toprak pH'sı yüksek kalmaktadır.

Toplam azot: Toprakların N (azot) kapsamlarının çalışma alanı içerisindeki örneklenen noktalardan tahmin edilmesi için en uygun semivariogram model parametreleri dikkate alınarak yersel değişim haritası elde edilmiş (Şekil 4) ve N (\% olarak) tahmin değerlerinin $\% 0.16$ ile \%0.29 arasında değiştiği belirlenmiştir. Bu göreceli yükseklik, ürün artıkları içeren ve organik gübre kullanılan topraklarda organik madde miktarı ile ilişkili olabilir (Huang ve ark., 2007).

Topraktaki N'un mineralizasyonu, hareketliliği, bitkiler tarafından alınabilirliği; toprağın yapısı, pH'sı, toprağın sulanabilirliği, iklim koşulları v.s. gibi etmenlerle ilişkilidir (Kacar, 2013; Uygur ve ark., 2010). Toplam azot içeriği potansiyel olarak bitkinin zamanla faydalanabileceği $\mathrm{N}$ miktarı (Kara ve ark., 2006) hakkında bilgi veren daha çok toprak organik maddesi ile ilişkili bir özelliktir. Bu nedenle $\mathrm{N}$ içeriği; toprağın fiziksel, kimyasal, mikrobiyolojik özellikleri üzerinde önemli bir etkiye sahiptir. Bu parametrenin optimum değeri; farklı toprak gruplarında ve her bir bitki için farklık gösterebilmektedir. Bu bağlamda farklı amenajman koşullarında örneğin tarım, çayır ve çalılık alanlarda $\mathrm{N}$ orta derecede bir değişkenlik göstermiş ve sıralama azdan çoğa doğru; tarım alanı, çayır ve çalııı olarak belirlenmiştir (Wang ve ark., 2009).

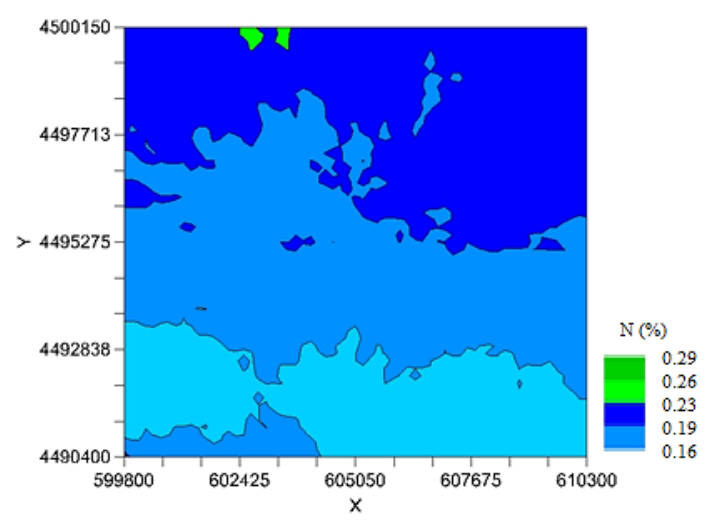

Şekil 4. Toprakların Kjeldahl azot konsantrasyonunun değişim paterni

Figure 4. Spatial pattern of Kjeldahl nitrogen concentration in soils

Harita incelendiğinde tarımın yoğun olarak yapıldığı alanlarda N değerleri \%0.16 - \%0.19 arasında çıkmıştır. $\mathrm{Bu}$ da arazinin güney kısmında toplanmıştır. Toprakta $\% 0.16 \mathrm{~N}$ yeterlilik sınır değerinin üstündedir, ancak bu Bayat topraklarında tarım yapılırken azotlu gübreleme yapılmasına intiyaç olmadığı anlamına gelmemektedir. Dolaylı olarak böğe topraklarının organik madde açısından mineral topraklar için istenilen \%2-4 aralığında olduğuna işaret etmektedir. Bu da oluşturulan haritada turkuaz mavisi rengin olduğu bölgeyi göstermektedir. Tarım yoğunluğunun az olduğu alanlarda $\mathrm{N}$ değerleri \%0.19- 0.29 arasında çıkmıştır. Tarım yapılmayan ya da yoğunluğunun az olduğu alanlarda $\mathrm{N}$ miktarının yüksek olması bölgede uygulanan tarım tekniği nedeniyle toprakların organik madde içeriklerinin azalma eğiliminde olduğuna ya da toprak özelliklerinin bozulma yolunda olduğuna işaret etmektedir.

Yarayışlı fosfor: Toprakların yarayışlı fosfor konsantrasyonlarının $6.5-10.8 \mathrm{mg} \mathrm{kg}^{-1}$ arasında değiştiği tahmin edilmiş olup, $\mathrm{P}^{\prime}$ nin çalışma sahasındaki yersel değişimi Şekil 5' te gösterilmiştir.

Topraktaki P'nin yarayışlılığı; toprak yapan faktörlerin etkisiyle herhangi bir zamandaki toprağın fiziksel, kimyasal, biyolojik özellikleri ile uygulanan girdi ve amenajman yöntemlerinin bir sonucudur. Toprakta Olsen yöntemiyle belirlenen $P$ için yeterlilik sınırları 8-25 $\mathrm{mg} \mathrm{kg} \mathrm{kg}^{-1}$ arasındadır (Alpaslan ve ark., 2005). Harita incelendiğinde tarımın yoğun olarak yapıldığı alanlarda P konsantrasyonu $6.5-8.7 \mathrm{mg} \mathrm{kg}^{-1}$ arasında iken; tarım yoğunluğunun az olduğu alanlarda $8.7-10.8 \mathrm{mg} \mathrm{kg}^{-1}$ arasında değişmiştir. Haritada yeşil ve tonlarının olduğu bölge $\mathrm{P}$ bakımından yeterlidir ve haritanın orta bölgesinde yoğunlaşmıştır. Yöre topraklarının genelde kireçli ve $\mathrm{pH}>7$ olması nedeniyle gübre ile verilen $\mathrm{P}$ büyük oranda trikalsiyum fosfat şeklinde fiske olarak faydası azalmaktadır (Uygur ve Karabatak, 2009). Yağışlar ile topraktan bitki besin elementlerinin yıkanarak uzaklaştırılması, toprakta yarayışlı organizmaların iklim etkisi ile etkinliğinin zayıf olması $P$ üzerinde etkili olan etmenlerdir. Flüvyal bölgede biyolojik olarak kullanılabilen $P$ ve toplam $C d$ geleneksel çiftlik tarım ve mineral gübrenin aşırı kullanılmasından dolayı aynı bileşende toplanmıştır (Romic ve ark., 2012).

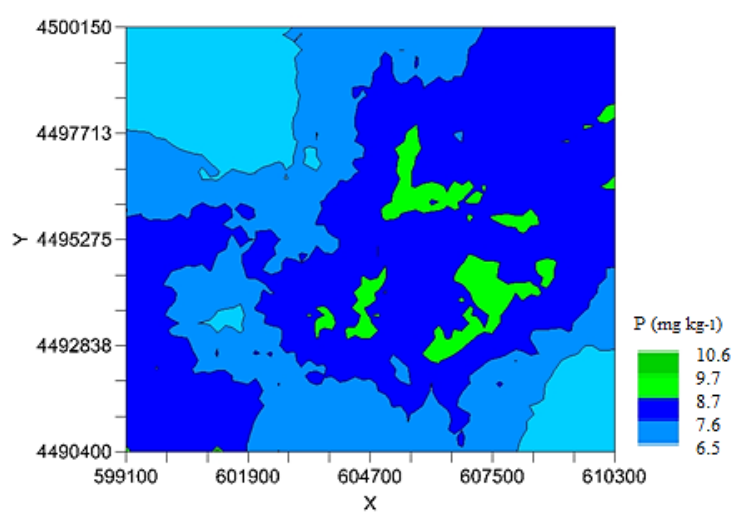

Şekil 5. Toprakların yarayışı fosfor konsantrasyonunun değişim paterni

Figure 5. Spatial pattern of available phosphorus concentration in soils 
Toprak Tekstürü: Topraktaki su ve besin elementlerinin tutulması, katyon değişim kapasitesi kum, kil ve silt dağılımı ile ilgilidir. Kumlu toprakların su tutma kapasitesi düşük olduğu için makro ve mikro besinleri tutması güçtür. Bu da bitkilerde besin elementi noksanlığına neden olmaktadır. Başka bir sınırlayıcı faktör olmadığı durumlarda genellikle yüksek kil içeriğine sahip topraklarda verim yüksektir (Cox ve ark., 2003).

Çalışma alanına ait \% kil değişim paterni incelendiğinde, kil miktarının \%24.3-71.4 gibi geniş bir aralıkta olduğu görülmektedir. Çalışma alanında genelde kil içeriği \% 50

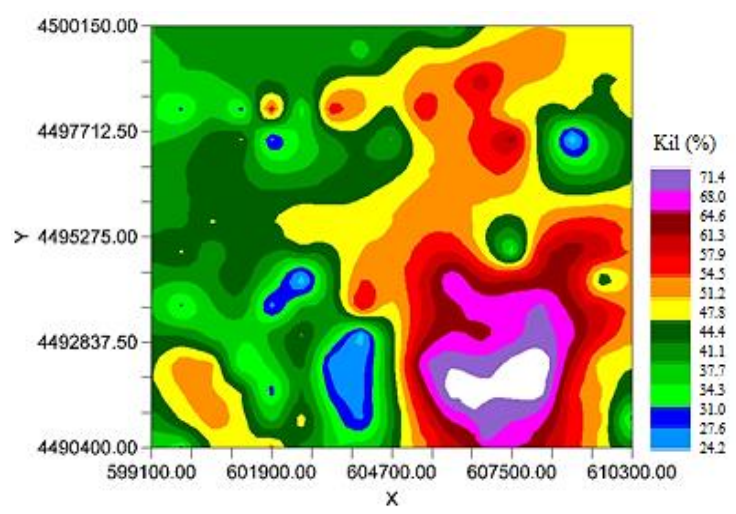

ve üzeri olan bölgeler ağır killi topraklar olup kuzey-doğu ve güney-doğu yönlerinde yoğunlukla dağılım göstermektedir (Şekil 6a).

Çalışma alanında kum fraksiyonun \% 6.5-42.5 aralığında olduğu görülmektedir. Toprakların geneli \%21 ve daha az kum içermektedir. Arazinin yüksekliği arttıkça kum miktarı artmaktadır ve bu bölgeler arazinin engebeli, dağlık ve tepelik alanlarına denk gelmektedir (Şekil 1, 6b). Bu da arazide erozyon riskinin yüksekliği ile ilişkilendirilebilir. Kumun en düşük olduğu yerde ise eğim düz ve düze yakındır (Şekil 1)

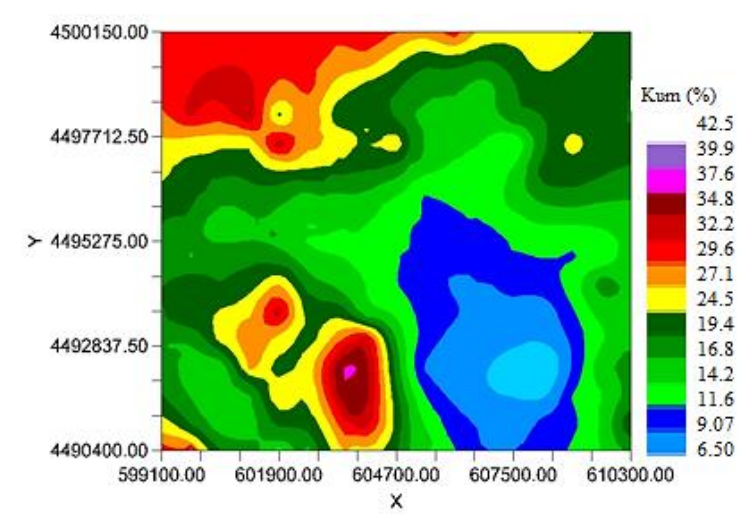

Şekil 6. Toprakların a) kil b) kum fraksiyonlarının değişim paterni Figure 6. Spatial pattern of clay (a) and sand (b) fractions in soils

Kireç Eşdeğeri: Ölçülen parametreler arasında en güçlü modele sahip toprak özelliğidir. Nitekim, kalsiyum karbonatın mesafeye bağlı dağılımının tahmininde bu çalışmada olduğu gibi kriging yöntemi oldukça başarılıdır (Sarmadian ve ark., 2010). Toprakların kireç değerlerinin çalışma alanı içerisindeki örneklenen noktalardan tahmin edilmesi için en uygun semivariogram model parametreleri dikkate alınarak elde edilmiş ve kireç tahmin değerlerinin \%5 ile \%24.8 arasında değiştiği belirlenmiştir.

Topraktaki kireç miktarı bitkiler için önemlidir. Kireç miktarının artması ile pH'da yükselir. Kireç miktarının azalması ile $\mathrm{pH}$ düşer ve toprak asidik özellik kazanır. Böyle bir durumda diğer besin elementlerinin yarayışııığını arttırmak, asitliğin zararlı etkilerini azaltmak, toprağın fiziksel özelliğini düzeltmek ve mikrobiyolojik faaliyetin artmasını sağlamak için toprağa kireç ilave etmek gerekir.

Toprakta Ca miktarı arttıkça, alınabilir fosfor ve demir iyonları Ca ile çözünmez formda bileşik oluşturur. Bitki, topraktaki demir ve fosfordan yararlanamaz. Toprakta kireç miktarının düşük olması da bitki beslenmesi açısından sakıncalıdır. Çünkü Ca bitki hücre duvarının yapısında bulunmaktadır. Böyle bir durumda bitkide $\mathrm{Ca}$ eksikliği görülebilmektedir.
Çalışma alanına ait toprak kireç değişim paterni incelendiğinde (Şekil 7), kireç değerinin \%5-14,9 arasında orta kireçli olduğunu bununda haritada mavi renk tonunda gösterilerek ovanın hemen hemen bütün kısmını kapladığı görülmektedir.

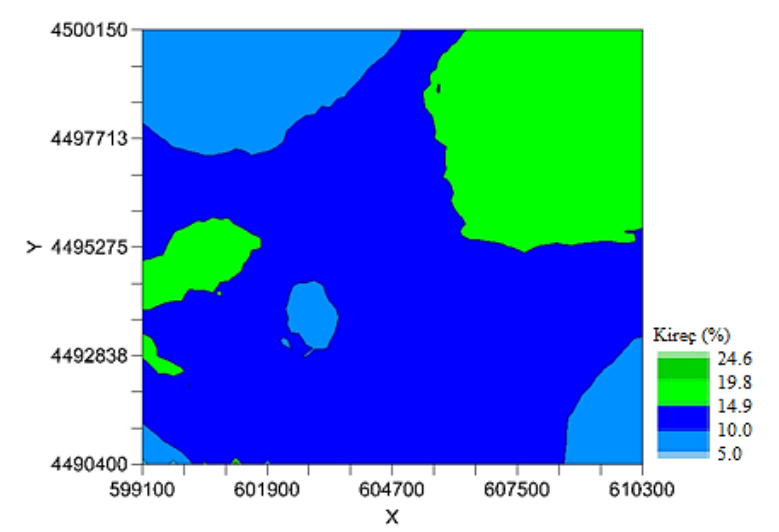

Şekil 7. Toprakların kireç içeriğinin değişim paterni Figure 7. Spatial pattern of carbonate content in soils

$\mathrm{Bu}$ bölgedeki kireç miktarı genel itibari ile yeterli seviyededir. Kireç miktarının \%14,9-24,8 aralığında fazla kireçli olduğu bununda yeşil renk tonlarında gösterilerek ovanın kuzeydoğu ve batı kısmında olduğu görülmüştür. illçe merkezi olan çalışma alanının kuzey doğusu tuz gölünün de işaret ettiği üzere bir birikme bölgesidir. 
Dolayısıyla yüksek kısımlardan gelen karbonatlı eriyikler bu bölgede sekonder karbonatlar şeklinde çökelerek birikme ya da yıkanmanın az olmasına bağlı olarak bu kısımlarda karbonat miktarında bir artış gerçekleşmiştir. pH: Çalışma alanı topraklarının pH tahmin değerlerinin 6.92-7.76 arasında nötrden hafif alkaliye değiştiği belirlenmiştir (Usta, 1995). Çalışma alanı genel itibari ile incelendiğinde mavi ve tonlarının olduğu bölge yükselti ve dere yatağının olması nedeni ile $\mathrm{pH}$ bakımından daha düşük, yeşil ve tonlarının olduğu bölgelerde bitkisel üretim yapıldığı ve su etkisinin az olduğu yerler $\mathrm{pH}$ bakımından biraz daha yüksek, turuncu ve kırmızı bölge yükseltiden ve dağlık alan olmasından dolayı bitkisel üretimin daha az yapıldığı yerlerde $\mathrm{pH}^{\prime} \mathrm{n} ı n$ daha da yükseldiği görülmüştür (Şekil 8).

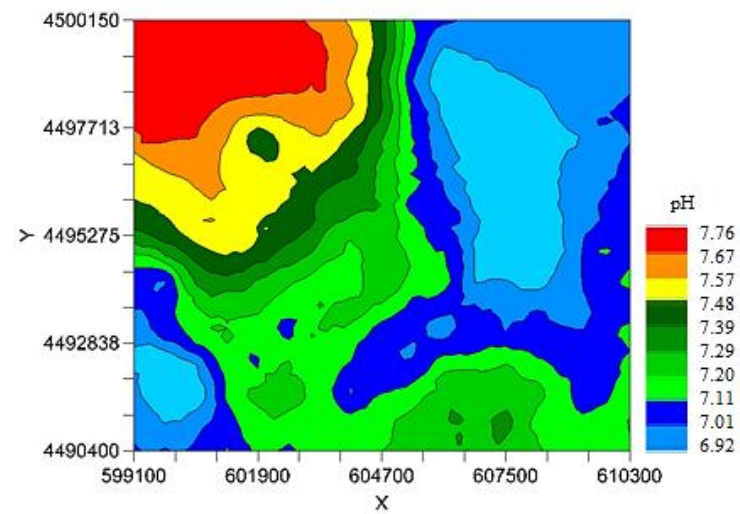

Şekil 8. $\mathrm{pH}^{\prime}$ nın çalışma alanındaki değişim paterni

Figure 8. Spatial pattern of $\mathrm{pH}$ in the study area

Toprak pH'sı tüm bitki besinlerinin çözünürlüğü, hareket kabiliyeti ve elverişliliğini etkileyen önemli bir faktördür (Kacar, 2013; Usta, 1995). Bu nedenle aynı özelliğe sahip bir toprakta besin elementlerinin elverişliliği ve bitkilerce alımı $\mathrm{pH}$ değerleri ile yakından ilgilidir. Toprak $\mathrm{pH}$ 'sının 6.5-7.4 (nötr) arasında olması hemen hemen tüm besin elementlerinin alınabilirliği açısından yeterli sayılabilecektir. pH'nın yüksek olduğu bu bölge topraklarında bazı bitki besin elementinin çözünürlüğü ve elverişliliği azalmakta bazılarının toksik düzeyde artması söz konusu olabilmektedir. Bundan dolayı bu bölge topraklarından birim alandan daha yüksek verim alabilmek için $\mathrm{pH}$ 'nın düşürülmesine katkı sağlayan tarımsal pratiklerin uygulanmasına ihtiyaç vardır.

\section{Diğer Parametreler}

Bayat ilçesi tarım arazilerinde elektriksel iletkenlik, organik madde, mesafeye bağlı bir değişim modeline göre dağılmayıp rastgele bir dağılım göstermektedirler. Bu etkiyi ortadan kaldırmak için araziden $700 \mathrm{~m}$ den daha kısa mesafeden daha çok örnekleme yapılması gerektiği değerlendirilmiştir.
Bu çalışmada Çorumun Bayat ilçesinin topraklarının bazı verimlilik parametreleri incelenmiştir. Yapılan inceleme sonucunda oluşturulan değişim paterni haritalarında kireç \%5.0-24.8, değişebilir+çözünebilir K 270-750 mg kg1, Na 39.6-370.9 mg kg-1, N \%0.16-0.29, pH 6.92-7.761, P 6.5-10.8 $\mathrm{mg} \mathrm{kg}^{-1}$ aralığında olduğu tespit edilmiştir. Yapılan incelemelere göre kireç ve $\mathrm{pH}^{\prime}$ nın yetiştiricilik açısından önemli bir problem olmadığı, organik maddenin düşük, fosforun ise yetersiz olduğu görülmüştür.

Incelenen bölgede ana materyal, topoğrafya, iklim, buharlaşma ve buharlaşma (ET), tarımsal girdiler, mikroorganizma faaliyetleri gibi sebeplerin etkisiyle topraktaki $\mathrm{P}, \mathrm{K}, \mathrm{KDK}$, kireç, $\mathrm{Na}$ ve $\mathrm{pH}$ özelliklerinde mesafeye bağlı değişimler görülmektedir.

Fosfor bakımından yeterli alanlar çok az bir yer tutarken fosfor bakımından yetersiz alanlar arazinin geriye kalanını oluşturmaktadır. Bu durumda ovada mutlaka fosfor yönetimine ve gübrelemesine azami dikkat gösterilmelidir.

Toprak organik maddesi ve elektriksel iletkenlik örnek yoğunluğunun yetersizliği nedeni ile mesafeye bağlı bir ilişki bulunmadığından; bu parametrelerin bir modele bağlı dağılım göstermediği, yani nugget model olduğu, belirlenmiştir.

Yüksekliğin fazla olduğu yerlerde yağış ve akarsular nedeniyle $\mathrm{Na}$ iyonunu yıkayarak daha düz eğimli arazilerde birikme gösterdiği belirlenmiştir. Bu durum artan tuzluluk ve nötr $\mathrm{pH}$ ile kendini göstermiştir. Bu birikme nedeniyle $\mathrm{Na}$ iyonu konsantrasyonu/tuzluluk düz alanlarda özelikle çalışma alanının güneydoğu kısmında problem oluşturabileceği düşünülmektedir.

\section{ÖZET}

Amaç: Bu çalışmanın amacı, Çorum ili Bayat ilçesine ait Kızılırmak kıyısında kalan bazı tarım alanlarında toprak verimlilik parametrelerinin yersel değişkenliğini grit yöntemiyle alınan kompozit toprak örneklerinde yapılan analizlerle belirlemek ve haritalamaktır.

Yöntem ve Bulgular: Kompozit yüzey toprağı örnekleri 700x700 m mesafeyle oluşturulan gritlerin kesişim noktalarından alınmıştır. Topraklarda pH, EC, kireç (\%), organik madde (\%), toplam azot, yarayışı fosfor, değişebilir $\mathrm{Ca}, \mathrm{K}$ ve $\mathrm{Na}$ ve toprak bünyesi gibi parametreler belirlenmiştir. Daha sonra bu parametrelerin yersel değişkenliği kriging yöntemiyle modellenerek yersel değişim haritaları oluşturulmuştur.

Genel Yorum: Incelenen parametrelerden $\mathrm{K}, \mathrm{Na}, \mathrm{P}, \mathrm{N}$, kireç, $\mathrm{pH}$, kil ve kumun mesafeye bağımlı bir değişiklik gösterdiği belirlenmiştir. Diğer parametreler ise nugget model göstermiştir. Toprakların genelinde fosfor 
yetersizliği gözlenmiştir. pH ve EC'nin çalışma alanında önemli bir problem oluşturmadığı gözlenmiştir, fakat zamanla güney batı kesimlerinde yıkanmaya bağlı tuzluluk riski bulunmaktadır.

Çalışmanın Önemi ve Etkisi: Topraklarda yersel değişkenliğin bilinmesi girdi kullanımının daha etkin olmasını ve tarımsal uygulamaların çevreye duyarlı olmasını sağlamaktadır.

Anahtar Kelimeler: Toprak verimliliği, Mesafeye bağlı değişim, Kriging, Bayat, Çorum, Toprak özellikleri

\section{TEŞEKKÜR}

Bu Çalışma Hatay Mustafa Kemal Üniversitesi Bilimsel Araştırma Projeleri Komisyonunca Desteklenmiştir

\section{ÇIKAR ÇATIŞMA BEYANI}

Yazar(lar) çalışma konusunda çıkar çatışmasının olmadığını beyan eder.

\section{ARAŞTIRMACILARIN KATKI ORANI BEYANI}

Yazarlar arasında herhangi bir çıkara çatışması bulunmamaktadır.

\section{KAYNAKLAR}

Alpaslan M, Güneş A, İnal A (2005). Deneme Tekniği. Ankara Üniversitesi Ziraat Fakültesi Yayınları No: $1501,437 \mathrm{~s}$.

Alves L A, Denardin LGD, Martins AP, Anghinoni I, Carvalho PCD, Tiecher T (2019) Soil acidification and $\mathrm{P}, \mathrm{K}, \mathrm{Ca}$ and $\mathrm{Mg}$ budget as affected by sheep grazing and crop rotation in a long-term integrated croplivestock system in southern Brazil. Geoderma 351:197-208.

Anonim (2009) Çorum Valiliği il Tarım Müdürlüğü Çorum'da Tarım 2009 Yıllığı. Çorum.

Anonim (2010) Çorum ilii Tarım Master Planı. Çorum.

Behera SK, Mathur RK, Shukla AK, Suresh K, Prakash C (2018) Spatial variability of soil properties and delineation of soil management zones of oil palm plantations grown in a hot and humid tropical region of southern India Catena 165:251-259.

Castrignano A, Goovaerts P, Lulli L, Bragato G (2000) A geostatistical approach to estimate probability of occurrence of Tuber melanosporum in relation to some soil properties. Geoderma 98: 95-113.

Cheng, Y T, Li P, Xu GC, Li ZB, Gao HD, Zhao BH, Wang T, Wang FC, Cheng SD (2018) Effects of soil erosion and land use on spatial distribution of soil total phosphorus in a small watershed on the Loess Plateau, China. Soil Till. Res. 184:142-152.
Cheng, QL, Guo YJ, Wang WL, Hao SL (2014) Spatial variation of soil quality and pollution assessment of heavy metals in cultivated soils of Henan Province, China. Chem. Spec. Bioavailab. 26(3):184-190.

Cox MS, Gerard PD, Wardlaw MC, Abshire MJ (2003). Variability of selected soil properties and their relationships with soybean yield. Soil Sci. Soc. Am. J. 67(4):1296-1302.

de Oliveira JC, Souza LCD, Melo VD (2010) Variability of soil physical and chemical properties in different plot divisions of the Guabirotuba formation. Rev. Bras. Cien. Solo 34:1491-1502.

Dobermann A, Goovaerts P George T (1995) Sources of soil variation in an acid ultisol of the Philippines. Geoderma 68: 173-191.

Duan, LX, Li ZW, Xie HX, Li ZM, Zhang L, Zhou Q (2020) Large-scale spatial variability of eight soil chemical properties within paddy fields. Catena 188:104350.

Gama Design Software (2008) Geostatistics for Environmental Science. Plainwell, Michigan, USA.

Goderya FS (1998) Field scale variations in soil properties for spatially variable control: A review. J. Soil Contam. 7: 243-264.

Hamlett JM, Horton R, Cressie NAC (1986) Resistant and exploratory techniques for use in semivariogram analysis. Soil Sci. Soc. Am. J. 50: 868-875.

Heijting S, de Bruin S, Bregt AK (2011) The arable farmer as the assessor of within-field soil variation. Prec. Agric. 12: 488-507.

Huang HB, Ouyang W, Wu HT, Liu HB, Andrea C (2017) Long-term diffuse phosphorus pollution dynamics under the combined influence of land use and soil property variations. Sci Total Environ. 579:18941903.

Huang B, Sun WX, Zhao YC, Zhu J, Yang RQ, Zou Z, Ding F, Su JP (2007) Temporal and spatial variability of soil organic matter and total nitrogen in an agricultural ecosystem as affected by farming practices. Geoderma 139: 336-345.

Journel AD, Huijbregts CJ (1978) Mining Geostatistics. Academic Press, London.

Kacar B (2012) Toprak Analizleri. Nobel Yayınevi, Ankara. Kacar B (2013) Temel Gübre Bilgisi. Nobel Akademik Yayıncılık, Ankara.

Kara EE, Erel A, Uygur V (2006) The effects of composted poultry wastes on nitrogen mineralization and biological activity in a silt loam soil. J. Appl. Sci. 6(11): 2476-2480.

Lark RM (2002) Optimized spatial sampling of soil for estimation of the variogram by maximum likelihood. Geoderma 105: 49-80. 
Manning G, Fuller LG, Eilers RG, Florinsky I (2001) Soil moisture and nutrient variation within an undulating Manitoba landscape. Can. J. Soil Sci. 81: 449-458.

Miheretu BA, Yimer AA (2018) Spatial variability of selected soil properties in relation to land use and slope position in Gelana sub-watershed, Northern highlands of Ethiopia. Phys Geogr 39(3):230-245.

Qiu WW, Curtin D, Johnstone P, Beare $M$, HernandezRamirez G (2016) Small-scale spatial variability of plant nutrients and soil organic matter: an arable cropping case study. Commun. Soil Sci. Plan. 47(19): 2189-2199.

Rhoades JD, 1982 Cation exchange capacity, In: Methods of Soil Analysis Part 2 Chemical and Microbiological Properties, Second Edition, Agronomy No: 9, Part 2, P: 149-157.

Rockstrom J, Barron J, Brouwer J, Galle S, de Rouw A (1999) On-farm spatial and temporal variability of soil and water in pearl millet cultivation. Soil Sci. Soc. Am. J. 63:1308-1319.

Romic D, Romic M, Zovko M, Bakic H, Ondrasek G (2012) Trace metals in the coastal soils developed from estuarine floodplain sediments in the Croatian Mediterranean region. Environ. Geochem. Hlth. 34(4): 399-416.

Sarmadian F, Keshavarzi A, Malekian A (2010) Continuous mapping of topsoil calcium carbonate using geostatistical techniques in a semi-arid region. Aust. J Crop Sci. 56(5): 693-704.

Sawant SS, Nagaraju MSS, Srivastava R, Prasad J, Nasre RA, Mohekar DS (2018) Mapping of spatial variability in soil properties for site-specific nutrient management of Nagpur Mandarin in Central India. Indian J. Hortic. 75(2): 209-217.

Sezer S (2013) Bayat, Çorum, tarım alanlarının verimlilik parametrelerinin yersel değişkenliğinin belirlenmesi. Yüksek lisans Tezi, Mustafa Kemal Üniversitesi, Fen Bil. Enst., Toprak Bilimi ve Bitki Besleme ABD, $53 \mathrm{~s}$.

Shahandeh H, Wright AL, Hons FM, Lascano RJ (2005) Spatial and temporal variation of soil nitrogen parameters related to soil texture and corn yield. Agron. J. 97: 772-782.

Stein A, Corsten LCA (1991) Universal krigging and cokrigging as regression procedure. Biometrics 47: 575-587.
Stenger R, Priesack E, Beese F (2002) Spatial variation of nitrate-N and related soil properties at the plot-scale. Geoderma, 105: 259-275.

Usta S (1995) Toprak Kimyası. Ankara Üniversitesi Ziraat Fakültesi Yayınları, Ankara.

Uygur V, Irvem A, Karanlik S, Akis R (2010) Mapping of total nitrogen, available phosphorous and potassium in Amik Plain, Turkey. Environ. Earth Sci. 59(5):11291138.

Uygur V, Karabatak I (2009) The effect of organic amendments on mineral phosphate fractions in calcareous soils. J. Plant Nutr. Soil Sci. 172(3): 336345.

Vasu D, Singh SK, Sahu N, Tiwary $P$, Chandran $P$, Duraisami VP, Ramamurthy V, Lalitha M, Kalaiselvi B (2017) Assessment of spatial variability of soil properties using geospatial techniques for farm level nutrient management. Soil Till. Res. 169:25-34.

Voortman RL, Brouwer J, Albersen PJ (2004) Characterization of spatial soil variability and its effect on Millet yield on Sudano-Sahelian coversands in SW Niger. Geoderma 121: 65-82.

Wang ZC (1999) Geostatistics and Its Applications in Ecology (in Chinese). Science Press, Beijing, p: 162192.

Wang YQ, Zhang XC, Huang CQ (2009) Spatial variability of soil total nitrogen and soil total phosphorus under different land uses in a small watershed on the Loess Plateau, China. Geoderma 150: 141-149.

Webster R, Oliver M (2007) Geostatistics for Environmental Scientists. John Wileys \& Sons, Ltd, Sussex, UK.

Wu C F, Huang JY, Zhu H, Zhang LM, Minasny B, Marchant B, McBratney AB (2019) Spatial changes in soil chemical properties in an agricultural zone in southeastern China due to land consolidation. Soil Till. Res. 187: 152-160.

Yalçın M (2012) Amik Ovası'nda tuzlulukla ilgili toprak özelliklerinin yersel ve zamansal değişiminin jeoistatistik yöntemlerle araştırılması. Doktora Tezi, Mustafa Kemal Üniversitesi, Fen Bil. Enst., Toprak Bilimi ve Bitki Besleme Anabilim Dalı, $146 \mathrm{~s}$. 